\title{
Efficacy of Ultra-Early (<12 h), Early (12-24h), and Late (>24-138.5 h) Surgery with Magnetic Resonance Imaging-Confirmed Decompression in American Spinal Injury Association Impairment Scale Grades A, B, and C Cervical Spinal Cord Injury
}

\author{
Bizhan Aarabi,, ${ }^{1,2}$ Noori Akhtar-Danesh, ${ }^{3}$ Timothy Chryssikos, ${ }^{1}$ Kathirkamanathan Shanmuganathan, ${ }^{2}$ \\ Gary T. Schwartzbauer,, J. Marc Simard,, Joshua Olexa,, Charles A. Sansur,, Kenneth M. Crandall, \\ Harry Mushlin,, Matthew J. Kole, Elizabeth J. Le, Aaron P. Wessell, Nathan Pratt, ${ }^{1}$ Gregory Cannarsa, \\ Cara Lomangino, 2 Maureen Scarboro, ${ }^{2}$ Carla Aresco, ${ }^{2}$ Jeffrey Oliver, Nicholas Caffes, \\ Stephen Carbine, ${ }^{1}$ and Kanami Mori ${ }^{1}$
}

\begin{abstract}
In cervical traumatic spinal cord injury (TSCI), the therapeutic effect of timing of surgery on neurological recovery remains uncertain. Additionally, the relationship between extent of decompression, imaging biomarker evidence of injury severity, and outcome is incompletely understood. We investigated the effect of timing of decompression on long-term neurological outcome in patients with complete spinal cord decompression confirmed on postoperative magnetic resonance imaging (MRI). American Spinal Injury Association (ASIA) Impairment Scale (AIS) grade conversion was determined in 72 AIS grades A, B, and C patients 6 months after confirmed decompression. Thirty-two patients underwent decompressive surgery ultra-early $(<12 \mathrm{~h}), 25$ underwent decompressive surgery early (12-24h), and 15 underwent decompressive surgery late ( $>24-138.5 \mathrm{~h}$ ) after injury. Age, gender, injury mechanism, intramedullary lesion length (IMLL) on MRI, admission ASIA motor score, and surgical technique were not statistically different among groups. Motor complete patients $(p=0.009)$ and those with fracture dislocations $(p=0.01)$ tended to be operated on earlier. Improvement of one grade or more was present in $55.6 \%$ of AIS grade A, $60.9 \%$ of AIS grade B, and $86.4 \%$ of AIS grade $\mathrm{C}$ patients. Admission AIS motor score $(p=0.0004)$ and pre-operative IMLL $(p=0.00001)$ were the strongest predictors of neurological outcome. AIS grade improvement occurred in $65.6 \%, 60 \%$, and $80 \%$ of patients who underwent decompression ultra-early, early, and late, respectively $(p=0.424)$. Multiple regression analysis revealed that IMLL was the only significant variable predictive of AIS grade conversion to a better grade (odds ratio, 0.908; confidence interval [CI], $0.862-0.957 ; p<0.001)$. We conclude that in patients with post-operative MRI confirmation of complete decompression following cervical TSCI, pre-operative IMLL, not the timing of surgery, determines long-term neurological outcome.
\end{abstract}

Keywords: decompression; MRI; outcome; SCI; timing of surgery

\section{Introduction}

$\mathbf{T}$ HE PATHOPHYSIOLOGY of cervical traumatic spinal cord injury (TSCI) is complex, and there remains no effective treatment for this high-impact disorder. ${ }^{1-6}$ In cervical TSCI, there is disruption of the anatomic integrity of the vertebral column followed by endothelial, neuronal, and axonal damage within fractions of a second of the injury. Continued compression of the spinal cord during the ensuing hours culminates in ischemia, swelling, and hemorrhagic progression of a compressive contusion. ${ }^{7-9}$ In this scenario, a deleterious cycle of events ensues, in which molecular cascades instigate the upregulation of cationic channels that promote secondary injury and edema, which is visible on magnetic resonance imaging (MRI) within $10 \mathrm{~min}$ and ultimately

\footnotetext{
${ }^{1}$ Department of Neurosurgery and ${ }^{2}$ R. Adams Cowley Shock Trauma Center, University of Maryland School of Medicine, Baltimore, Maryland.

${ }^{3}$ School of Nursing and Department of Health Research Methods, Evidence, and Impact, McMaster University, Hamilton, Ontario, Canada.

(C) Bizhan Aarabi et al., 2019; Published by Mary Ann Liebert, Inc. This Open Access article is distributed under the terms of the Creative Commons License (http://creativecommons.org/licenses/by/4.0), which permits unrestricted use, distribution, and reproduction in any medium, provided the original work is properly credited.
} 
leads to further compression of the injured spinal cord. ${ }^{10,11}$ The swollen spinal cord becomes compressed circumferentially and longitudinally against the dura mater and rigid bone at the injury epicenter and beyond, resulting in the displacement of cerebrospinal fluid and the effacement of the subarachnoid space across multiple vertebral segments. ${ }^{7,11-13}$

Compression of the spinal cord against an unyielding spinal canal results in increased intraspinal pressure and reduced perfusion pressure, further jeopardizing blood flow to the spinal cord. ${ }^{14-16}$ In motor complete TSCI patients, swelling of the spinal cord spreads rostrally and caudally from the injury epicenter in fusiform fashion, ${ }^{8}$ at a rate of $\sim 900 \mu \mathrm{m} / \mathrm{h} .{ }^{13,17}$ Frequently, by the time the victim is transferred to the trauma center, intramedullary lesion length (IMLL), can measure between 40 and $100 \mathrm{~mm}$ in length, far beyond the cross-sectional injury epicenter. ${ }^{18-20}$ Pre-clinical studies indicate that the longer the spinal cord is compressed, the more severe is the parenchymal damage and loss of function. ${ }^{21-24}$ Together, these findings have encouraged many trauma spine surgeons to recommend early operative intervention as a neuroprotective measure in order to promote neurological improvement. ${ }^{25-30}$

Ongoing surgical studies on the relationship among imaging biomarkers, surgical strategy, and long-term clinical outcome are shaping the standard of care for these patients. ${ }^{18,28,31-36}$ Over the past 30 years, overarching evidence has supported spinal cord decompression following trauma, but the question of surgical timing has yet to be established within this evolving paradigm..$^{10,12,32,35,37-41}$ In addition, although multiple reports have indicated that early anatomical alignment of the spinal column and decompression of the spinal cord followed by internal fixation is neuroprotective, in these studies, decompression of the spinal cord generally has not been verified by post-operative imaging.

Recent efforts have begun to establish the significance of the extent of spinal cord decompression in neurological outcome. ${ }^{16,35,42,43}$ Data reported by Aarabi and coworkers indicated that standard surgical management of cervical SCI achieves decompression of the entire swollen segment of the spinal cord in only $66 \%$ of subjects. ${ }^{35}$ Additional studies incorporating post-operative MRI indicate that up to $25 \%$ of patients may need expansive duraplasty for adequate spinal cord decompression, along with reduction of intraspinal pressure, in order to improve functional outcome. ${ }^{14,15,42,44,45}$ As a result, studies on the effect of timing of surgical intervention have likely been confounded by incomplete spinal cord decompression, and, therefore, the effect of timing on outcome remains uncertain. ${ }^{28,30,46-48}$

The null hypothesis was that in patients with subaxial cervical TSCI and post-operative MRI confirmation of decompression, the timing of surgery has no effect on long-term improvement in American Spinal Injury Association (ASIA) Impairment Scale (AIS) grade conversion.

\section{Methods}

\section{Design}

This study was a retrospective analysis of prospectively collected data.

\section{Cohort}

Over a 13-year period, from January 1, 2005 to December 31, 2017, 950 MRI-proven isolated cervical TSCI patients were admitted to this level I trauma center for management. From this cohort, we screened and selected 72 patients who were eligible for this investigation. The inclusion criteria were being $\geq 16$ years of age; Glasgow Coma Scale (GCS) score $\geq 14$; no concurrent life- threatening injury or disease; imaging studies compatible with subaxial cervical spine fracture dislocations; available good quality pre- and post-operative computed tomography (CT) and MRI studies indicating complete spinal cord decompression following surgery; ${ }^{35}$ and follow-up of at least 6 months after trauma and surgical management. The exclusion criteria were being obtunded, stuporous, and non-testable; having penetrating subaxial TSCI; having upper cervical SCI; a post-operative MRI indicating inadequate spinal cord decompression; non-operative management; having had a cervical CT myelogram and not an MRI as the primary imaging study; dying or being lost to follow-up; or having poorquality imaging studies. This study was performed after approval from the institutional review board (IRB) of the Human Research Protection Office (HRPO).

\section{Resuscitation, survey, and neurological examination}

Patients were transferred to the trauma resuscitation unit (TRU) by emergency medical technicians (EMTs). ${ }^{49}$ We received intubated and non-intubated patients supine on a backboard with the head and neck secured with a hard collar and chin strap. Median scene or transfer time after the accident was $1 \mathrm{~h}$ (mean, 2.3; standard deviation [SD], 3; range, $0.3-15 \mathrm{~h}$ ). In the TRU, primary and secondary examinations were performed by one of three teams of trauma surgeons who received the patients. Once the patients were medically stable, members of the neurosurgical team (senior resident or nurse practitioners) first examined and then presented them to the attending neurosurgeon. Admission ASIA motor score and AIS grade were determined according to the International Standards for Neurological Classification of Spinal Cord Injury (ISNCSCI) ${ }^{50}$ ASIA motor scores and AIS grades, which were used for statistical calculation were the ones with no effect from sedatives, analgesics, or mental confusion. In the majority of our patients, the TRU examination was definitive; however, in a minority of patients, the neurological examination within the first $72 \mathrm{~h}$ following trauma was used once the sedatives, analgesics and anesthetics were cleared from the patient's body.

\section{Imaging studies}

Eligible patients had imaging studies performed when they were medically stable. Cervical spine CT was performed within a median of $2 \mathrm{~h}$ (mean, 3.2; SD, 3.1; range, 3.5-15.8 h) and MRI was performed within a median of $5.8 \mathrm{~h}$ (mean, 7.2; SD, 5.1; range, 2.4$39.5 \mathrm{~h}$ ) from the time of the accident. The median time between the accident and MRI was $5 \mathrm{~h}$ for the ultra-early patients (mean $5.9 \mathrm{~h}$, range $3-12 \mathrm{~h}$ ), $6 \mathrm{~h}$ for the early patients (mean $6.8 \mathrm{~h}$, range 2.9 $14 \mathrm{~h}$ ), and $6 \mathrm{~h}$ for the late patients (mean $10.4 \mathrm{~h}$, range $3.5-39.5 \mathrm{~h}$ ). Fracture morphology was based on the Harris and coworkers, ${ }^{51}$ Allen and coworkers, ${ }^{52}$ and AO Spine ${ }^{53}$ classification systems. Admission T2-weighted and short T1 inversion recovery (STIR) sequences were used to measure the IMLL and the extent of spinal cord compression/decompression before and after surgery. ${ }^{18,35} \mathrm{An}$ attending trauma neuroradiologist and the principal investigator independently measured the IMLL, and the mean value was taken for statistical analysis. ${ }^{18}$

\section{Medical management}

From 2005 to 2009,22 of the study patients were administered methylprednisolone following SCI: $30 \mathrm{mg} / \mathrm{kg}$ within the first hour and $5.4 \mathrm{mg} / \mathrm{kg} / \mathrm{h}$ for the next $23 \mathrm{~h} .{ }^{54}$ In 2010 , this trauma center stopped the use of steroids for SCI. Patients' mean arterial blood pressure was maintained between 85 and $90 \mathrm{~mm} \mathrm{Hg}$ for 7 days following trauma. ${ }^{54,55}$

\section{Traction and surgical intervention}

When indicated, we applied traction for the reduction of cervical spine deformities immediately following CT and/or MRI 
Table 1. Baseline Characteristics of the Present Cohort

\begin{tabular}{|c|c|c|c|c|c|}
\hline Category & $<12$ h post-trauma & 12-24 h post-trauma & 24-138.5 h post-trauma & Total & $\mathrm{p}$ \\
\hline Accident $(\%)$ & & & & & 0.59 \\
\hline Fall & $14(38.9)$ & $14(38.9)$ & $8(22.2)$ & $36(50)$ & \\
\hline MVC & $12(60)$ & $5(25)$ & $3(15)$ & $20(27.8)$ & \\
\hline Other & $6(37.5)$ & $6(37.5)$ & $4(25)$ & $16(2.2)$ & \\
\hline Total & $32(44.4)$ & $25(34.7)$ & $15(20.8)$ & $72(100)$ & \\
\hline Gender $(\%)$ & & & & & 0.89 \\
\hline Male & $26(43.3)$ & $21(35)$ & $13(21.7)$ & $60(83.3)$ & \\
\hline Female & $6(50)$ & $4(33.3)$ & $2(16.7)$ & $12(16.7)$ & \\
\hline Total & $32(44.5)$ & $25(34.7)$ & $15(20.8)$ & $72(100)$ & \\
\hline Age (years): Mean (SD) & $41.8(18.4)$ & $49.4(18.3)$ & $49.3(13.2)$ & $46.0(17.6)$ & 0.19 \\
\hline AIS grade $(\%)$ & & & & & 0.009 \\
\hline AIS A & $13(48.2)$ & $11(40.7)$ & $3(11.1)$ & $27(37.5)$ & \\
\hline AIS B & $14(60.9)$ & $7(30.4)$ & $2(8.7)$ & $23(31.9)$ & \\
\hline AIS C & $5(22.7)$ & $7(31.8)$ & $10(45.5)$ & $22(30.6)$ & \\
\hline ASIA motor score: Mean (SD) & $18.6(14.4)$ & $22.0(15.2)$ & $24.5(14.2)$ & $21.1(14.6)$ & 0.40 \\
\hline Morphology (\%) & & & & & 0.01 \\
\hline $\mathrm{A} 0$ & $5(20)$ & $12(48)$ & $8(32)$ & $25(34.7)$ & \\
\hline $\mathrm{A} 3 / \mathrm{A} 4 / \mathrm{C}$ & $24(61.5)$ & $11(28.2)$ & $4(10.3)$ & $39(54.2)$ & \\
\hline $\mathrm{B} 2 / \mathrm{B} 3$ & $3(37.5)$ & $2(25)$ & $3(37.5)$ & $8(11.1)$ & \\
\hline Total & $32(44.5)$ & $25(34.7)$ & $15(20.8)$ & $72(100)$ & \\
\hline IMLL (mm): Mean (SD) & $43.3(19.5)$ & $37.5(17.9)$ & $30.6(13.9)$ & $38.6(18.4)$ & 0.07 \\
\hline Surgical technique $(\%)$ & & & & & 0.32 \\
\hline ACDF & $5(50)$ & $2(20)$ & $3(30)$ & $10(13.9)$ & \\
\hline ACDF+Laminectomy & $10(40)$ & $11(44)$ & $4(16)$ & $25(34.7)$ & \\
\hline $\mathrm{ACCF}$ & $7(77.8)$ & $2(22.2)$ & $0(0)$ & $9(12.5)$ & \\
\hline ACCF+Laminectomy & $5(45.4)$ & $4(36.4)$ & $2(18.2)$ & $11(15.3)$ & \\
\hline Laminectomy & $5(29.4)$ & $6(35.3)$ & $6(35.3)$ & $17(23.6)$ & \\
\hline Total & $32(44.4)$ & $25(34.7)$ & $15(20.8)$ & $72(100)$ & \\
\hline
\end{tabular}

MVC, motor vehicle crash; SD, standard deviation; AIS, American Spinal Injury Association (ASIA) Impairment Scale; IMLL, intramedullary lesion length; ACDF, anterior cervical discectomy and fusion; ACCF, anterior cervical corpectomy and fusion.

studies. ${ }^{35,56}$ We set up traction in the TRU, on a Stryker Wedge Turning Frame (Stryker Global Headquarters, Kalamazoo, Michigan) using real-time fluoroscopy. We applied incremental weights of 2-4 kgs per skeletal segment within a maximum of 30-45 min. If this was not successful, we reduced the deformity during surgery. Twenty patients had traction for unilateral $(n=3)$ or bilateral $(n=14)$ jumped facets or for compression fracture with $>3 \mathrm{~mm}$ translation $(n=3)$. We did not apply skeletal traction in 52 patients for several reasons: no evidence of fracture dislocation $(n=17)$; flexion or extension injury without translation $(n=20)$; compression fracture with $<3 \mathrm{~mm}$ translation $(n=12)$; or unilateral locked facets $(n=3)$.

\section{Surgical management}

Patients were decompressed and internally fixed within a median of $12 \mathrm{~h}$ (mean, 18.8; SD, 19.4; range, 4.5-138.5 h). Thirty-two

Table 2. Ais Grade Conversion in 32 Patients With Ultra-Early $(<12 \mathrm{H})$ Decompression

\begin{tabular}{lcccccc}
\hline \multicolumn{7}{c}{ AIS grade at follow-up } \\
\hline Admission AIS grade & A & B & C & D & E & Total \\
A & 5 & 5 & 3 & 0 & 0 & 13 \\
B & $2 *$ & 3 & 6 & 3 & 0 & 14 \\
C & 0 & 0 & 1 & 3 & 1 & 5 \\
\hline
\end{tabular}

*AIS grade regression.

AIS, American Spinal Injury Association (ASIA) Impairment Scale.
(44.5\%) patients were operated on in $<12 \mathrm{~h}, 25(34.7 \%)$ were operated on within $12-24 \mathrm{~h}$, and $15(20.8 \%)$ were operated on $>24$ $138.5 \mathrm{~h}$ after the trauma. Nine neurosurgeons including four spine fellowship-trained neurosurgeons performed the surgeries. Surgeries included anterior cervical discectomy and fusion (ACDF) in $10, \mathrm{ACDF}+$ laminectomy in 25; anterior cervical corpectomy and fusion $(\mathrm{ACCF})$ in 9; $\mathrm{ACCF}+$ laminectomy in 11; and only laminectomy in $17 .^{35,46,57}$ Post-operative CT and MRI were performed to confirm appropriate technique and to verify spinal cord decompression. Post-operative MRI studies were performed within a median of $34 \mathrm{~h}$ (mean, 45.1; SD, 30.8; range, 13.5-148.5 h). Postoperative MRI in the ultra-early group was performed a median of $31.5 \mathrm{~h}$ following trauma (mean 34.2, range 13.5-95.5 h). In the early group, the median time following trauma was $29.8 \mathrm{~h}$ (mean 42.4 and range $18.8-139.5 \mathrm{~h}$ ). In the late group, the median time following trauma to MRI was $56.9 \mathrm{~h}$ (mean 72.9 and range 39.8-148.5 h). Two spine fellowship-trained neurosurgeons, one

Table 3. Ais Grade Conversion in 25 Patients With EARly (12-24 h) Decompression

\begin{tabular}{lcccccc}
\hline \multicolumn{7}{c}{ AIS grade at follow-up } \\
\hline AIS grade at admission & A & B & C & D & E & Total \\
A & 6 & 1 & 2 & 2 & 0 & 11 \\
B & 0 & 3 & 3 & 1 & 0 & 7 \\
C & 0 & $1 *$ & 0 & 6 & 0 & 7 \\
\hline
\end{tabular}

*AIS grade regression.

AIS, American Spinal Injury Association (ASIA) Impairment Scale. 
Table 4. Ais Grade Conversion in 15 Patients With Late (>24-138.5 H) DeCOMPRESSION

\begin{tabular}{lcccccc}
\hline \multicolumn{7}{c}{ AIS grade at follow-up } \\
\hline Admission AIS grade & A & B & C & D & E & $\begin{array}{c}\text { Total admission } \\
\text { AIS grade }\end{array}$ \\
A & 1 & 1 & 0 & 1 & 0 & 3 \\
B & 0 & 1 & 0 & 1 & 0 & 2 \\
C & 0 & 0 & 1 & 9 & 0 & 10 \\
\hline
\end{tabular}

AIS, American Spinal Injury Association (ASIA) Impairment Scale. fellowship-trained neurotrauma neurosurgeon, a trauma neuroradiologist, and the principal investigator independently verified complete spinal cord decompression on postoperative MRI studies. ${ }^{35}$ Spinal cord decompression was defined as presence of cerebrospinal fluid in the subarachnoid space around the spinal cord circumferentially in all patients.

\section{Post-operative ICU care and follow-up}

The post-operative course in the ICU included deep vein thrombosis (DVT) prophylaxis by enoxaparin (Lovenox ${ }^{\circledR}$, Sanofi, USA), $30 \mathrm{mg}$ twice daily starting within $24-48 \mathrm{~h}$ of admission, and

Table 5. Ais Grade Conversion in Various Categories of the Cohort

\begin{tabular}{|c|c|c|c|c|}
\hline Category & AIS not converted & AIS converted & Total & $\mathrm{p}$ value \\
\hline Accident $(\%)$ & & & & 0.638 \\
\hline Fall & $12(33.3)$ & $24(66.7)$ & $36(50)$ & \\
\hline MVC & $8(40)$ & $12(60)$ & $20(27.8)$ & \\
\hline Other & $4(25)$ & $12(75)$ & $16(22.2)$ & \\
\hline Total & $24(33.3)$ & $48(66.7)$ & $72(100)$ & \\
\hline Gender $(\%)$ & & & & 0.18 \\
\hline Male & $22(36.7)$ & $38(63.3)$ & $60(83.3)$ & \\
\hline Female & $2(16.7)$ & $10(83.3)$ & $12(16.7)$ & \\
\hline Age (SD) & $40.8(16.2)$ & $48.6(17.9)$ & $46.0(17.6)$ & 0.07 \\
\hline Admission AIS grade $(\%)$ & & & & 0.058 \\
\hline A & $12(44.4)$ & $15(55.6)$ & $27(37.5)$ & \\
\hline $\mathrm{B}$ & $9(39.1)$ & $14(60.9)$ & $23(31.9)$ & \\
\hline $\mathrm{C}$ & $3(13.6)$ & $19(86.4)$ & $22(30.6)$ & \\
\hline Total & $24(33.3)$ & $48(66.7)$ & $72(100)$ & \\
\hline Admission ASIA motor score (SD) & $12.7(12.5)$ & $25.2(13.9)$ & $21.0(14.6)$ & 0.0004 \\
\hline Morphology (\%) & & & & 0.11 \\
\hline A0 (No evidence of fracture dislocation) & $6(24)$ & $19(76)$ & $25(34.7)$ & \\
\hline B2 or B3 (Flexion or extension injury) & $1(12.5)$ & $7(87.5)$ & $8(11.1)$ & \\
\hline $\mathrm{A} 3 / 4+\mathrm{C}$ (Significant translation in $\mathrm{X} / \mathrm{Y} / \mathrm{Z}$ axes) & $17(43.6)$ & $22(56.4)$ & $39(54.2)$ & \\
\hline \multicolumn{5}{|l|}{ Intramedullary lesion length (IMLL) (mm, SD) } \\
\hline Admission grade $\mathrm{A}$ & $59.3(20.7)$ & $35.6(9.6)$ & $46.1(19.4)$ & 0.002 \\
\hline Admission grade B & $54.2(19.1)$ & $31.9(11.9)$ & $40.6(18.4)$ & 0.003 \\
\hline Admission grade $\mathrm{C}$ & $23.9(17.1)$ & $27.9(9.9)$ & $27.4(10.6)$ & 0.472 \\
\hline Total & $53.0(22.1)$ & $31.5(10.7)$ & $38.6(18.4)$ & 0.00001 \\
\hline Surgical intervention $(\%)$ & & & & NS \\
\hline $\mathrm{ACDF}$ & $3(30)$ & $7(70)$ & $10(13.9)$ & \\
\hline ACDF+Laminectomy & $5(20)$ & $20(80)$ & $25(34.7)$ & \\
\hline ACCF & $1(11.1)$ & $8(88.9)$ & $9(12.5)$ & \\
\hline ACCF+Laminectomy & $9(81.8)$ & $2(18.2)$ & $11(15.3)$ & \\
\hline Laminectomy & $6(35.3)$ & $11(64.7)$ & $17(23.6)$ & \\
\hline Timing of surgery $(\%)$ & & & & 0.424 \\
\hline$<12 \mathrm{~h}$ after trauma & $11(34.4)$ & $21(65.6)$ & $32(44.5)$ & \\
\hline $12-24 \mathrm{~h}$ after trauma & $10(40)$ & $15(60)$ & $25(34.7)$ & \\
\hline$>24 \mathrm{~h}$ after trauma & $3(20)$ & $12(80)$ & $15(20.8)$ & \\
\hline Total & $24(33.3)$ & $48(66.7)$ & $72(100)$ & \\
\hline
\end{tabular}

AIS, American Spinal Injury Association (ASIA) Impairment Scale; MVC, motor vehicle crash; SD, standard deviation; ACDF, anterior cervical discectomy and fusion; ACCF, anterior cervical corpectomy and fusion.

Table 6. Multivariate Regression Analysis Comparing the Therapeutic Efficacy of Timing Of Surgery Versus INTRAMEDULLARY LESION LENGTH (IMLL)

\begin{tabular}{lccc}
\hline Outcome & Odds ratio & 95\% confidence interval & $\mathrm{p}$ value \\
\hline$<12 \mathrm{~h}$ trauma-surgery & Referent & - & - \\
12-24 h trauma-surgery & 0.455 & $0.118-1.752$ & 0.25 \\
$>24 \mathrm{~h}$ trauma-surgery & 0.832 & $0.141-4.88$ & 0.83 \\
IMLL $(\mathrm{mm})$ & 0.908 & $0.862-0.957$ & 0.001 \\
\hline
\end{tabular}


screening by duplex ultrasound for venous thromboembolism (VTE). When needed, patients had early tracheostomy for ventilator support and percutaneous gastroenterostomy for nutrition. When fully weaned from ventilator support, the patients were transferred to rehabilitation centers. While in the ICU, daily neurological examination including digital rectal examination was performed to determine ASIA motor score and evidence for AIS grade conversion. Following discharge, the patients returned at 6 weeks, 3 months, 6 months, and 12 months (or longer) for followup neurological examinations. Certified neurologists, rehabilitation specialists, the principal investigator, senior residents, and nurse practitioners performed neurological examinations to document any change in ASIA motor score and AIS grade conversion. ${ }^{18,35}$

\section{Results}

\section{Initial patient characteristics}

Age, gender, injury mechanism, IMLL, ASIA motor score, and surgical technique did not differ significantly among the three groups of patients: those with ultra-early $(<12 \mathrm{~h})$, early $(12-24 \mathrm{~h})$, or late (> 24-138.5 h) decompression (Table 1). Compared with AIS grade $\mathrm{C}$ patients, AIS grade $\mathrm{A}$ and $\mathrm{B}$ patients were operated on significantly earlier after admission $(p=0.009)$. Similarly, patients with burst/compression fractures and those with facet dislocations (types A3/A4 and $\mathrm{C}$ of the Vaccaro and coworkers AO Spine classification $^{53}$ ) were surgically managed earlier than patients with no evidence of fractures and horizontal translation (AO Spine Class types A0, B2, B3) on CT and MRI ( $p=0.01)$

\section{AIS grade conversion}

During a period of at least 6 months of follow-up, three patients had regression of their AIS grade compared with at admission. In the ultra-early group, two patients in the AIS grade B group converted to AIS grade A, and in the early group, one patient in the AIS grade C group regressed to AIS grade B (Tables 2-6). The effect of nine independent variables on AIS grade conversion when the spinal cord was completely decompressed on post-operative MRI was analyzed. From the demographic variables, neither age $(p=0.07)$ nor gender $(p=0.18)$ had any influence on AIS grade conversion. The mechanism of injury also was without effect on neurological outcome $(p=0.638)$. Patients with higher ASIA motor score at admission had a better rate of conversion at 6 months $(p<0.0004)$, but the rate of conversion was not influenced by admission AIS grade $(p=0.058)$. One reason for lack of congruity between ASIA motor score and AIS grade could be the fact that AIS grade is a composite of ASIA motor score, sensation, and sacral sparing, which could have unknown confounding statistical effects on each other. Regarding the CT scan of the cervical spine, regardless of whether there were no fracture/dislocations (A0) or fracture/dislocation along one or multiple axes (AO Spine classification morphology types A3/A4, B2/B3, C), morphology type did not affect grade conversion $(p=0.11) .{ }^{53}$ Five different surgical techniques were used for complete decompression of the spinal cord. ${ }^{35}$ The type of surgical technique did not affect neurological outcome (Fig. 1). Contrary to much of the literature (see Table 7), surgical decompression in any of the three time periods had no effect on improvements in AIS grade conversion $(p=0.424){ }^{28,47,58,59}$ Intramedullary lesion length (IMLL) on T2W or STIR images, as a surrogate end-point biomarker, had the most powerful effect on AIS grade conversion $(\mathrm{p}=0.001) .{ }^{18,35,60-62}$ Compared with patients who had no improvement in AIS grade, patients with grade conversion had significantly shorter IMLL on pre-operative T2W or STIR MRI
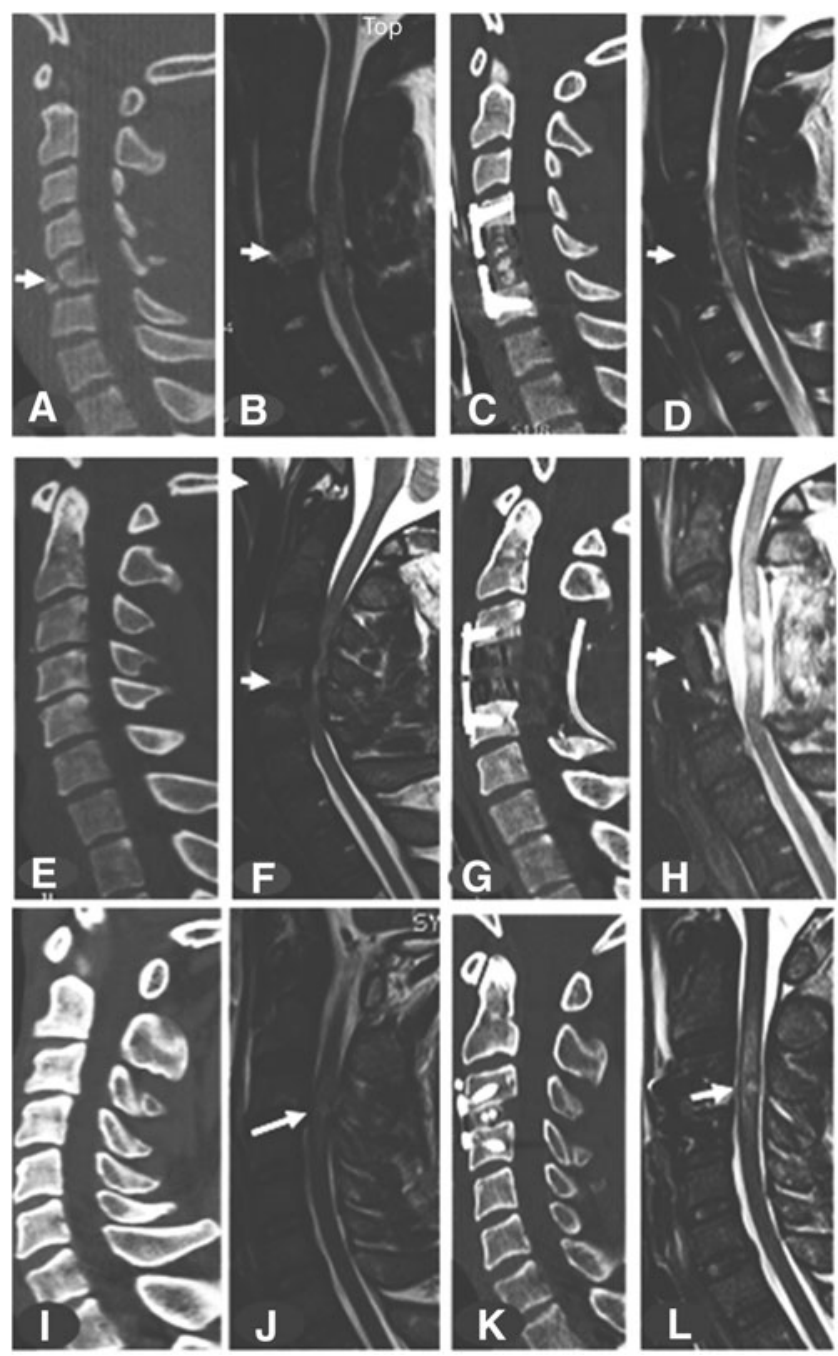

FIG. 1. (A-D) Midsagittal computed tomography (CT) and magnetic resonance imaging (MRI) of a 19-year-old man involved in an automobile accident who was admitted 30 min later to the trauma resuscitation unit (TRU) with a C5 compression tear-drop fracture (arrow); American Spinal Injury Association (ASIA) motor score of 21, and ASIA Impairment Scale (AIS) grade B; intramedullary lesion length (IMLL) at admission was $27.8 \mathrm{~mm}$. A C5 corpectomy was performed $6 \mathrm{~h}$ after the accident, which completely decompressed the spinal cord. MRI $34.5 \mathrm{~h}$ after surgery indicated an IMLL of $34.4 \mathrm{~mm}$. One year following the accident, his ASIA motor score was 64 and he was AIS grade D. (E-H) Midsagittal CT and MRI of a 42-year-old man who had a mechanical fall and was admitted 30 min later to the TRU with from spinal stenosis and possible extension injury (arrow); ASIA motor score was 8 and AIS grade was A; IMLL at admission was $42.2 \mathrm{~mm}$. He underwent C4 corpectomy and C3-C5 laminectomy with fusion $13 \mathrm{~h}$ after the accident, with complete spinal cord decompression. MRI $23 \mathrm{~h}$ after surgery indicated an IMLL of $30.9 \mathrm{~mm}$. Six months following the accident, his ASIA motor score remained 8 and he was AIS grade A. (I-L) Midsagittal CT and MRI of a 53-year-old man who had a mechanical fall and was admitted $10.5 \mathrm{~h}$ later to the TRU with a $\mathrm{C} 3 / 4$ extension injury (arrow); ASIA motor score was 33 and AIS grade was C; IMLL at admission was $20.3 \mathrm{~mm}$. He underwent discectomy and fusion at $\mathrm{C} 3 / 4,36 \mathrm{~h}$ after the accident, with complete spinal cord decompression. MRI $49.8 \mathrm{~h}$ after surgery indicated an IMLL of $49.6 \mathrm{~mm}$. Fifty-seven months following the accident, his ASIA motor score was 91 and he was AIS grade D. 
Table 7. Investigations Evaluating the Timing of Decompression on the Therapeutic Effectiveness and Neurological Outcome in Cervical Traumatic Spinal Cord Injury

\begin{tabular}{|c|c|c|c|c|c|c|c|c|c|c|}
\hline $\begin{array}{l}\text { Investigator } \\
\text { Year Journal }\end{array}$ & Design & Cohort & $\begin{array}{c}\text { AIS } \\
\text { grade }\end{array}$ & $\begin{array}{c}\text { Preop } \\
\text { MRI }\end{array}$ & $\begin{array}{l}\text { Timing } \\
\text { (hours) }\end{array}$ & $\begin{array}{c}\text { Postop } \\
\text { MRI }\end{array}$ & $I M L L$ & $\begin{array}{c}\text { Extent of } \\
\text { DEC. }\end{array}$ & $F / U M$ & $\begin{array}{l}\text { TE/AIS grade } \\
\text { conversion }\end{array}$ \\
\hline $\begin{array}{l}\text { Vaccaro et al. } \\
\text { Spine, } 1997\end{array}$ & PR & 62 & A-D & Yes & $\leq 72$ and $>120$ & No & No & No & 11.5 & No effect \\
\hline $\begin{array}{l}\text { Guest et al. } \\
\text { J. Neurosurg., } 2002\end{array}$ & RO & 50 & C-D & Yes & $\leq 24$ and $>24$ & No & No & No & 36 & $\begin{array}{l}\text { Not } \\
\text { mentioned }\end{array}$ \\
\hline $\begin{array}{l}\text { Papadopoulos et al. } \\
\text { J. Trauma } 2002\end{array}$ & PO & 91 & A-D & Yes & $<12$ and $>12$ & No & No & No & 33 & $\begin{array}{l}\text { Early } \\
\text { superior }\end{array}$ \\
\hline $\begin{array}{l}\text { Sapkas and Papadakis } \\
\text { J. Orthop. Surg. } 2007\end{array}$ & RO & 67 & A-E & Yes & $\leq 72$ and $>72$ & No & No & No & 48 & No effect \\
\hline Lenehan et al. Spine 2010 & $\mathrm{PO}$ & 73 & C-D & Yes & $\leq 24$ and $>24$ & No & No & No & 12 & No effect \\
\hline $\begin{array}{l}\text { Wilson et al. Spinal } \\
\text { Cord } 2012\end{array}$ & PO & 55 & A-D & Yes & $<24$ and $\geq 24$ & No & No & No & 3 & $\begin{array}{l}\text { Early } \\
\text { superior }\end{array}$ \\
\hline $\begin{array}{l}\text { Fehlings et al. PLoS } \\
\text { One } 2012\end{array}$ & PO & 313 & A-D & Yes & $<24$ and $\geq 24$ & No & No & No & 6 & $\begin{array}{l}\text { Early } \\
\text { superior }\end{array}$ \\
\hline $\begin{array}{l}\text { Jug et al. J. Neurotrauma } \\
2015\end{array}$ & PO & 42 & A-C & Yes & $\leq 8$ and $8-24$ & No & No & No & 6 & $\begin{array}{l}\text { Early } \\
\text { superior }\end{array}$ \\
\hline $\begin{array}{l}\text { Dvorak et al. } \\
\text { J. Neurotrauma } 2015\end{array}$ & PO & 470 & A-D & Yes? & $\leq 24$ and $>24$ & No & No & No & $3-6$ & NM \\
\hline $\begin{array}{l}\text { Grassner et al. } \\
\text { J. Neurotrauma } 2016\end{array}$ & RO & 70 & A-D & Yes & $\leq 8$ and $8-90$ & No & No & No & 10 & $\begin{array}{l}\text { Early } \\
\text { superior }\end{array}$ \\
\hline $\begin{array}{l}\text { Bourassa-Moreau et al. } \\
\text { J. Neurotrauma } 2016\end{array}$ & PO & 20 & A & Yes & $<24-\geq 24$ & No & No & No & 5 & $\begin{array}{l}\text { Early } \\
\text { superior }\end{array}$ \\
\hline $\begin{array}{l}\text { Mattiassich et al. } \\
\text { J. Neurotrauma } 2017\end{array}$ & RO & 49 & A-D & Yes & $<5 \mathrm{~h}$ and $\geq 5-24$ & No & No & No & 6 & Late superior \\
\hline $\begin{array}{l}\text { Burke et al. } \\
\text { Neurosurgery } 2018\end{array}$ & RO & 48 & A-D & Yes & $\leq 12,12-24,>24$ & No & No & No & $\mathrm{ACD}$ & $\begin{array}{l}\text { Early } \\
\text { superior }\end{array}$ \\
\hline $\begin{array}{l}\text { Kim et al. World } \\
\text { Neurosurg. } 2018\end{array}$ & RO & 46 & A-D & Yes & $\leq 48$ and $>48$ & No & No & No & 6 & No effect \\
\hline $\begin{array}{r}\text { Sewell et al. World } \\
\text { Neurosurg. } 2018\end{array}$ & RO & 95 & A-D & Yes & $\leq 24$ and $>24$ & No & No & No & 6 & No effect \\
\hline $\begin{array}{l}\text { Current Study } \\
2019\end{array}$ & RO & 73 & A-C & Yes & $\begin{array}{l}\leq 12,12-24,24- \\
\quad 138.5\end{array}$ & Yes & Yes & Yes & 6 & No effect \\
\hline
\end{tabular}

AIS, American Spinal Injury Association (ASIA) Impairment Scale; MRI, magnetic resonance imaging; IMLL, intramedullary lesion length; ACD, acute care discharge; DEC, decompression; F/U, follow-up; $\mathrm{M}$, months; PO, prospective observational; PR, prospective randomized; RO, retrospective observational; TE, treatment effect.

images. Regression analysis of variables with no effect, marginal effect, or significant effect on AIS grade conversion indicated that IMLL had the most powerful influence on improved grade conversion at 6 months following trauma (Table 6).

\section{Discussion}

The principal finding of the present study is that, in a cohort of patients with cervical TSCI with pre-operative MRI evidence of spinal cord compression and post-operative MRI evidence of complete decompression, it was the IMLL, not the timing of surgery, that best predicted improved AIS grade conversion.

A meta-analysis of pre-clinical studies ${ }^{63,64}$ on experimental TSCI concluded that neuroprotection may be obtained when decompression is performed early following injury. However, in the studies subjected to meta-analysis, the degree of compression was difficult to compare directly because of important methodological differences, with some studies introducing spacers to narrow the canal diameter, others compressing the cord with aneurysm clips or weights exerting different forces, and others compressing the cord with devices exerting known pressures. In a rodent pre-clinical study by Batchelor and coworkers, a sustained compression force of $\sim 35 \mathrm{~mm} \mathrm{Hg}$ quickly resulted in paraplegia. ${ }^{65} \mathrm{In}$ a meta-analysis by the same investigators, early decompression improved behav- ioral outcome in rodents and non-human primates by up to $35 \%$. $^{64}$ Although supportive of early decompression, the pre-clinical studies included in Batchelor's meta-analysis were heterogeneous in design, methodology, and timing of decompression, and these studies suffered from low internal validity and reporting bias. Translating data from pre-clinical models to humans has repeatedly proven to be very difficult. ${ }^{63,64}$

The therapeutic effectiveness of timing (early vs. late) of surgical decompression and its relationship with neurological outcome following cervical TSCI is at equipoise (Table 7). ${ }^{2,30,59,66,67}$ Heterogeneity in design, methodology, surgical technique, neurological assessment, timing of decompression, number of patients enrolled, length of follow-up, and outcome assessment tools used makes interpretation of the results difficult and the therapeutic effectiveness of timing of decompression uncertain. Notably, most of the studies published during the past 20 years have confirmed preoperative spinal cord compression by CT or MRI, but seldom has there been a precise, anatomic definition of the term decompression, the purported goal of surgery. In many studies, the surgical technique, including the number of discectomies, corpectomies, or laminectomies in isolation or in combination required to decompress the swollen spinal cord was not well documented. $28,30,46,47,68$ Almost universally, decompressive surgery was not followed by post-operative MRI to verify complete decompression of a swollen 
spinal cord. ${ }^{28,29,47,48,58,59,66-73}$ By contrast, Papadopoulos and coworkers, ${ }^{47}$ and Sapkas and Papadakis, ${ }^{67}$ used MRI following closed traction reduction to assess for any residual compression following anatomical realignment and to decide on the need for further spinal cord decompression. In the multi-center prospective observational study by Fehlings and coworkers, ${ }^{28}$ postoperative MRI was performed only in patients who had neuroworsening following surgical decompression. These studies uniformly used CT scan evidence of injury morphology as a guide for surgical intervention, not the IMLL or the extent of swelling across several skeletal segments present on preoperative MRI. In a recent clinical study, standard surgical approaches as recommended by Dvorak and coworkers ${ }^{57}$ were successful in decompressing the swollen spinal cord in only $66 \%$ of AIS grade A and B patients. ${ }^{35}$ Another study in AIS grade $\mathrm{A}, \mathrm{B}$, and $\mathrm{C}$ patients indicated that complete decompression resulted in AIS grade conversion in 58.9\% of patients, whereas inadequate decompression resulted in improved AIS grade conversion in only $18.6 \%$ of patients. ${ }^{18}$ Adequate laminectomy is the procedure that is the sine qua non for assured spinal cord decompression. ${ }^{35}$ In the latter series, almost $74 \%$ of patients had to have multi-level laminectomies for adequate decompression of the swollen spinal cord. By contrast, the rate of laminectomy in the randomized study of Vaccaro and coworkers ${ }^{30}$ was $9.6 \%$, and in the prospective observational study of Jug and coworkers, ${ }^{29}$ it was $7 \%$. Therefore, the surgical methodology in these two series could have confounded the interpretation of the effect of timing of decompression on neurological outcome. In published articles discussing the timing of decompression and neurological outcome, MRI-documented IMLL, an important predictor of neurological outcome, was not used to guide the extent of surgery required for adequate spinal cord decompression. ${ }^{18,20,61,62,74-78}$

In addition to imaging biomarkers such as structural MRI, which convey a visual indication of compression, studies have revealed the importance of juxtaluminal pressure measurements inside the parenchyma of the spinal cord. ${ }^{42,43,79}$ The presence of a swollen spinal cord against nonyielding dura may indicate a requirement for expansive duraplasty. ${ }^{43}$ In the current study, $100 \%$ of the patients had an open subarachnoid space (as a prerequisite inclusion criterion); therefore, the need for a juxtaluminal pressure monitor is less clear. However in a previous report from the University of Maryland, only 7 of 63 patients $(11 \%)$ with inadequate bony decompression also exhibited effaced subarachnoid space, therefore being candidates for intraspinal pressure monitoring and expansive duraplasty. ${ }^{35}$ Consideration of intraspinal pressure and spinal cord perfusion pressure and pressure reactivity index may help improve neurological outcomes following inadequate bony decompression performed within the appropriate time window following trauma. ${ }^{22,45,80,81}$

Apart from structural MRI, which is mandatory for the diagnosis, pre-operative planning, estimation of the degree of spinal cord compression, IMLL, and the extent of spinal cord decompression, quantitative MRI (QMRI) biomarkers including magnetization transfer, relaxation mapping, and diffusion imaging have helped us better understand secondary changes following TSCI at a microstructural level across the entire neuraxis. ${ }^{36,82-87}$ QMRI depicts the extent of iron deposition in the spinal cord and brain and the degree of demyelination and degeneration, and it can predict neurological outcome and the degree of neural plasticity. ${ }^{36,83}$ These studies may be useful as surrogate end-points in trials on the timing of decompression and AIS grade conversion following TSCI. ${ }^{88-90}$

The present study underscores the emerging importance of injury severity parameters such as IMLL and Brain and Spinal Injury Center (BASIC) score, ${ }^{77}$ as well as the extent of decompression, in studies involving the timing of decompression. If future multicenter and prospective studies take into account IMLL and completeness of decompression, the actual effect of the timing of decompression in TSCI will likely be clarified.

Limitations of this study include the following.

1. The majority of the motor complete TSCI patients were in the ultra-early and early decompression categories, whereas the reverse was true for motor incomplete patients (AIS grade C) who were in the late decompression category.

2. In a minority of our patients, ISNCSCI examination, which was used for statistical analysis, was completed within $72 \mathrm{~h}$ of trauma when the effects of analgesics, sedatives, and anesthesia were absent and there was no mental confusion.

\section{Conclusion}

Pre-clinical studies, biological rationale, and recent clinical investigations favor early spinal cord decompression to enhance motor outcome following TSCI. Many of the clinical trials to date have been heterogeneous, biased, and with low internal validity. These studies have been based on standard surgical procedures that rely on pre-operative CT and MRI, with no independent verification of the completeness of spinal cord decompression on post-operative MRI. In our study, when the spinal cord was shown to be decompressed on post-operative MRI, the timing of decompression did not influence AIS grade conversion. Here, we identified intramedullary lesion length as the main predictor of neurological outcome.

\section{Author Disclosure Statement}

No competing financial interests exist.

\section{References}

1. Chen, Y., He, Y., and DeVivo, M.J. (2016). Changing demographics and injury profile of new traumatic spinal cord injuries in the United States, 1972-2014. Arch. Phys. Med. Rehabil. 97, 1610-1619.

2. Curt, A., Van Hedel, H.J., Klaus, D., and Dietz, V. (2008). Recovery from a spinal cord injury: significance of compensation, neural plasticity, and repair. J. Neurotrauma 25, 677-685.

3. Krueger, H., Noonan, V.K., Trenaman, L.M., Joshi, P., and Rivers, C.S. (2013). The economic burden of traumatic spinal cord injury in Canada. Chronic diseases and injuries in Canada 33, 113-122.

4. Selvarajah, S., Hammond, E.R., Haider, A.H., Abularrage, C.J., Becker, D., Dhiman, N., Hyder, O., Gupta, D., Black, J.H., 3rd, and Schneider, E.B. (2014). The burden of acute traumatic spinal cord injury among adults in the united states: an update. J. Neurotrauma 31 , 228-238.

5. Kwon, B.K., Tetzlaff, W., Grauer, J.N., Beiner, J., and Vaccaro, A.R. (2004). Pathophysiology and pharmacologic treatment of acute spinal cord injury. Spine J. 4, 451-464.

6. Rowland, J.W., Hawryluk, G.W., Kwon, B., and Fehlings, M.G. (2008). Current status of acute spinal cord injury pathophysiology and emerging therapies: promise on the horizon. Neurosurg. Focus 25, E2.

7. Kurland, D., Hong, C., Aarabi, B., Gerzanich, V., and Simard, J.M. (2012). Hemorrhagic progression of a contusion after traumatic brain injury: a review. J. Neurotrauma 29, 19-31.

8. Balentine, J.D. (1978). Pathology of experimental spinal cord trauma. I. The necrotic lesion as a function of vascular injury. Lab. Invest. 39, 236-253.

9. Dohrmann, G.J., Wagner, F.C., Jr., and Bucy, P.C. (1972). Transitory traumatic paraplegia: electron microscopy of early alterations in myelinated nerve fibers. J. Neurosurg. 36, 407-415.

10. Bilgen, M., Abbe, R., Liu, S.J., and Narayana, P.A. (2000). Spatial and temporal evolution of hemorrhage in the hyperacute phase of experimental spinal cord injury: in vivo magnetic resonance imaging. Magn. Reson. Med. 43, 594-600. 
11. Simard, J.M., Tsymbalyuk, O., Ivanov, A., Ivanova, S., Bhatta, S., Geng, Z., Woo, S.K., and Gerzanich, V. (2007). Endothelial sulfonylurea receptor 1-regulated NC Ca-ATP channels mediate progressive hemorrhagic necrosis following spinal cord injury. J. Clin. Invest. 117, 2105-2113.

12. Ahuja, C.S., Wilson, J.R., Nori, S., Kotter, M.R.N., Druschel, C., Curt, A., and Fehlings, M.G. (2017). Traumatic spinal cord injury. Nat. Rev. Dis. Primers 3, 17018.

13. Aarabi, B., Simard, J.M., Kufera, J.A., Alexander, M., Zacherl, K.M., Mirvis, S.E., Shanmuganathan, K., Schwartzbauer, G., Maulucci, C.M., Slavin, J., Ali, K., Massetti, J., and Eisenberg, H.M. (2012). Intramedullary lesion expansion on magnetic resonance imaging in patients with motor complete cervical spinal cord injury. Journal of neurosurgery. Spine 17, 243-250.

14. Chen, S., Smielewski, P., Czosnyka, M., Papadopoulos, M.C., and Saadoun, S. (2017). Continuous monitoring and visualization of optimum spinal cord perfusion pressure in patients with acute cord injury. J. Neurotrauma 34, 2941-2949.

15. Gallagher, M.J., Hogg, F.R.A., Zoumprouli, A., Papadopoulos, M.C., and Saadoun, S. (2019). Spinal cord blood flow in patients with acute spinal cord injuries. J. Neurotrauma 36, 919-929.

16. Hogg, F.R.A., Gallagher, M.J., Chen, S., Zoumprouli, A., Papadopoulos, M.C., and Saadoun, S. (2018). Predictors of intraspinal pressure and optimal cord perfusion pressure after traumatic spinal cord injury. Neurocrit. Care. [Epub ahead of print; DOI: 10.1007/s12028018-0616-7].

17. Le, E., Aarabi, B., Hersh, D.S., Shanmuganathan, K., Diaz, C., Massetti, J., and Akhtar-Danesh, N. (2015). Predictors of intramedullary lesion expansion rate on MR images of patients with subaxial spinal cord injury. J. Neurosurg. Spine, 22, 611-621.

18. Aarabi, B., Sansur, C.A., Ibrahimi, D.M., Simard, J.M., Hersh, D.S., Le, E., Diaz, C., Massetti, J., and Akhtar-Danesh, N. (2017). Intramedullary lesion length on postoperative magnetic resonance imaging is a strong predictor of ASIA impairment scale grade conversion following decompressive surgery in cervical spinal cord injury. Neurosurgery $80,610-620$.

19. Miyanji, F., Furlan, J.C., Aarabi, B., Arnold, P.M., and Fehlings, M.G. (2007). Acute cervical traumatic spinal cord injury: MR imaging findings correlated with neurologic outcome--prospective study with 100 consecutive patients. Radiology 243, 820-827.

20. Schaefer, D.M., Flanders, A., Northrup, B.E., Doan, H.T., and Osterholm, J. (1989). Magnetic resonance imaging of acute cervical spine trauma. Spine 14, 1090-1095.

21. Carlson, G.D., Gordon, C.D., Oliff, H.S., Pillai, J.J., and Lamanna, J.C. (2003). Sustained spinal cord compression: part I: time-dependent effect on long-term pathophysiology. J. Bone Joint Surg. Am. 85-A, 86-94.

22. Saadoun, S., Chen, S., and Papadopoulos, M.C. (2017). Intraspinal pressure and spinal cord perfusion pressure predict neurological outcome after traumatic spinal cord injury. J. Neurol. Neurosurg. Psychiatry $88,452-453$.

23. Kobrine, A.I., Evans, D.E., and Rizzoli, H. (1978). Correlation of spinal cord blood flow and function in experimental compression. Surg. Neurol. 10, 54-59.

24. Kobrine, A.I., Evans, D.E., and V., R.H. (1979). Experimental acute balloon compression of the spinal cord. Factors affecting disappearance and return of the spinal evoked response. J. Neurosurg. 51, 841845.

25. Anderson, K.K., Tetreault, L., Shamji, M.F., Singh, A., Vukas, R.R. Harrop, J.S., Fehlings, M.G., Vaccaro, A.R., Hilibrand, A.S., and Arnold, P.M. (2015). Optimal timing of surgical decompression for acute traumatic central cord syndrome: a systematic review of the literature. Neurosurgery 77, Suppl. 4, S15-32.

26. Cadotte, D.W., Singh, A., and Fehlings, M.G. (2010). The timing of surgical decompression for spinal cord injury. F1000 Med. Rep. 2, 67.

27. Fehlings, M.G., Sekhon, L.H., and Tator, C. (2001). The role and timing of decompression in acute spinal cord injury: what do we know? What should we do? Spine 26, S101-110.

28. Fehlings, M.G., Vaccaro, A., Wilson, J.R., Singh, A., D, W.C., Harrop, J.S., Aarabi, B., Shaffrey, C., Dvorak, M., Fisher, C., Arnold, P., Massicotte, E.M., Lewis, S., and Rampersaud, R. (2012). Early versus delayed decompression for traumatic cervical spinal cord injury: results of the Surgical Timing in Acute Spinal Cord Injury Study (STASCIS). PloS one 7, e32037.
29. Jug, M., Kejzar, N., Vesel, M., Al Mawed, S., Dobravec, M., Herman, S., and Bajrovic, F.F. (2015). Neurological recovery after traumatic cervical spinal cord injury is superior if surgical decompression and instrumented fusion are performed within 8 hours versus 8 to 24 hours after injury: a single center experience. J. Neurotrauma 32, 1385-1392.

30. Vaccaro, A.R., Daugherty, R.J., Sheehan, T.P., Dante, S.J., Cotler, J.M., Balderston, R.A., Herbison, G.J., and Northrup, B.E. (1997). Neurologic outcome of early versus late surgery for cervical spinal cord injury. Spine 22, 2609-2613.

31. Levi, A.D., Anderson, K.D., Okonkwo, D.O., Park, P., Bryce, T.N., Kurpad, S.N., Aarabi, B., Hsieh, J., and Gant, K. (2019). Clinical outcomes from a multi-center study of human neural stem cell transplantation in chronic cervical spinal cord injury. J. Neurotrauma $36,891-902$.

32. Ter Wengel, P.V., De Witt Hamer, P.C., Pauptit, J.C., van der Gaag, N.A., Oner, F.C., and Vandertop, W.P. (2019). Early surgical decompression improves neurological outcome after complete traumatic cervical spinal cord injury: a meta-analysis. J. Neurotrauma 36, 835-844.

33. Fehlings, M.G., Nakashima, H., Nagoshi, N., Chow, D.S., Grossman, R.G., and Kopjar, B. (2016). Rationale, design and critical end points for the Riluzole in Acute Spinal Cord Injury Study (RISCIS): a randomized, double-blinded, placebo-controlled parallel multi-center trial. Spinal Cord 54, 8-15.

34. Kucher, K., Johns, D., Maier, D., Abel, R., Badke, A., Baron, H., Thietje, R., Casha, S., Meindl, R., Gomez-Mancilla, B., Pfister, C. Rupp, R., Weidner, N., Mir, A., Schwab, M.E., and Curt, A. (2018). First-in-man intrathecal application of neurite growth-promoting antinogo-a antibodies in acute spinal cord injury. Neurorehabil. Neural Repair 32, 578-589.

35. Aarabi, B., Olexa, J., Chryssikos, T., Galvagno, S.M., Hersh, D.S., Wessell, A., Sansur, C., Schwartzbauer, G., Crandall, K., Shanmuganathan, K., Simard, J.M., Mushlin, H., Kole, M., Le, E., Pratt, N., Cannarsa, G., Lomangino, C.D., Scarboro, M., Aresco, C., and Curry, B. (2019). Extent of spinal cord decompression in motor complete (American Spinal Injury Association Impairment Scale Grades A and B) traumatic spinal cord injury patients: post-operative magnetic resonance imaging analysis of standard operative approaches. J. Neurotrauma 36, 862-876.

36. Seif, M., Curt, A., Thompson, A.J., Grabher, P., Weiskopf, N., and Freund, P. (2018). Quantitative MRI of rostral spinal cord and brain regions is predictive of functional recovery in acute spinal cord injury. NeuroImage Clin. 20, 556-563.

37. Wilson, J.R., Tetreault, L.A., Kwon, B.K., Arnold, P.M., Mroz, T.E., Shaffrey, C., Harrop, J.S., Chapman, J.R., Casha, S., Skelly, A.C., Holmer, H.K., Brodt, E.D., and Fehlings, M.G. (2017). Timing of decompression in patients with acute spinal cord injury: a systematic review. Global Spine J. 7, 95s-115s.

38. Hackney, D.B., Ford, J.C., Markowitz, R.S., Hand, C.M., Joseph, P.M., and Black, P. (1994). Experimental spinal cord injury: MR correlation to intensity of injury. J. Comput. Assist. Tomogr. 18, 357-362.

39. Simard, J.M., Popovich, P.G., Tsymbalyuk, O., Caridi, J., Gullapalli, R.P., Kilbourne, M.J., and Gerzanich, V. (2013). MRI evidence that glibenclamide reduces acute lesion expansion in a rat model of spinal cord injury. Spinal Cord 51, 823-827.

40. Collignon, F., Martin, D., Lenelle, J., and Stevenaert, A. (2002). Acute traumatic central cord syndrome: magnetic resonance imaging and clinical observations. J. Neurosurg. 96, 29-33.

41. Mihai, G., Nout, Y.S., Tovar, C.A., Miller, B.A., Schmalbrock, P., Bresnahan, J.C., and Beattie, M.S. (2008). Longitudinal comparison of two severities of unilateral cervical spinal cord injury using magnetic resonance imaging in rats. J. Neurotrauma 25, 1-18.

42. Phang, I., and Papadopoulos, M.C. (2015). Intraspinal pressure monitoring in a patient with spinal cord injury reveals different intradural compartments: Injured Spinal Cord Pressure Evaluation (ISCoPE) Study. Neurocrit. Care [Epub ahead of print; DOI: 10.1007/s12028015-0153-6].

43. Phang, I., Werndle, M.C., Saadoun, S., Varsos, G., Czosnyka, M., Zoumprouli, A., and Papadopoulos, M.C. (2015). Expansion duroplasty improves intraspinal pressure, spinal cord perfusion pressure, and vascular pressure reactivity index in patients with traumatic spinal cord injury: injured spinal cord pressure evaluation study. J. Neurotrauma $32,865-874$.

44. Chen, S., Gallagher, M.J., Hogg, F., Papadopoulos, M.C., and Saadoun, S. (2018). Visibility graph analysis of intraspinal pressure signal 
predicts functional outcome in spinal cord injured patients. J. Neurotrauma 35, 2947-2956.

45. Saadoun, S., and Papadopoulos, M.C. (2016). Spinal cord injury: is monitoring from the injury site the future? Crit. Care 20, 308.

46. Vale, F.L., Burns, J., Jackson, A.B., and Hadley, M.N. (1997). Combined medical and surgical treatment after acute spinal cord injury: results of a prospective pilot study to assess the merits of aggressive medical resuscitation and blood pressure management. J. Neurosurg. 87, 239-246.

47. Papadopoulos, S.M., Selden, N.R., Quint, D.J., Patel, N., Gillespie, B., and Grube, S. (2002). Immediate spinal cord decompression for cervical spinal cord injury: feasibility and outcome. J. Trauma 52, 323-332.

48. Burke, J.F., Yue, J.K., Ngwenya, L.B., Winkler, E.A., Talbott, J.F., Pan, J.Z., Ferguson, A.R., Beattie, M.S., Bresnahan, J.C., Haefeli, J., Whetstone, W.D., Suen, C.G., Huang, M.C., Manley, G.T., Tarapore, P.E., and Dhall, S.S. (2018). Ultra-early $(<12$ hours) surgery correlates with higher rate of american spinal injury association impairment scale conversion after cervical spinal cord injury. Neurosurgery 185 , 199-203.

49. Maryland Institute for Emergency Medical Services Systems. (2015). Maryland Institute for Emergency Medical Services Systems. https:// www.m.emss.org

50. American Spinal Injury Association (1992). International Standards for Neurological and Functional Classification of Spinal Cord Injury. Chicago: American Spinal Injury Association/International Spinal Cord Society

51. Harris, J.H., Jr., Edeiken-Monroe, B., and Kopaniky, D.R. (1986). A practical classification of acute cervical spine injuries. Orthop. Clin. North Am. 1, 15-30.

52. Allen, B.L., Jr., Ferguson, R.L., Lehmann, T.R., and O'Brien, R.P. (1982). A mechanistic classification of closed, indirect fractures and dislocations of the lower cervical spine. Spine 7, 1-27.

53. Vaccaro, A.R., Koerner, J.D., Radcliff, K.E., Oner, F.C., Reinhold, M., Schnake, K.J., Kandziora, F., Fehlings, M.G., Dvorak, M.F., Aarabi, B., Rajasekaran, S., Schroeder, G.D., Kepler, C.K., and Vialle, L.R. (2015). AOSpine subaxial cervical spine injury classification system. Eur. Spine J. [Epub ahead of print; DOI: 10.1007/s00586-0153831-3].

54. Hadley, M.N., Walters, B.C., Grabb, P.A., Oyesiku, N.M., Prezybylski, G.J., Resnick, D.K., Ryken, T.C., and Mielke, D.H. (2002). Guidelines for the Management of Acute Cervical Spine and Spinal Cord injuries. Neurosurgery 50, S1-S199.

55. Walters, B.C., Hadley, M.N., Hurlbert, R.J., Aarabi, B., Dhall, S.S., Gelb, D.E., Harrigan, M.R., Rozelle, C.J., Ryken, T.C., and Theodore, N. (2013). Guidelines for the management of acute cervical spine and spinal cord injuries: 2013 update. Neurosurgery 60, Suppl. 1, 82-91.

56. Lee, A.S., MacLean, J.C., and Newton, D.A. (1994). Rapid traction for reduction of cervical spine dislocations. J Bone Joint Surg. Br. 76 352-356

57. Dvorak, M.F., Fisher, C.G., Fehlings, M.G., Rampersaud, Y.R., Oner, F.C., Aarabi, B., and Vaccaro, A.R. (2007). The surgical approach to subaxial cervical spine injuries: an evidence-based algorithm based on the SLIC classification system. Spine 32, 2620-2629.

58. Grassner, L., Wutte, C., Klein, B., Mach, O., Riesner, S., Panzer, S., Vogel, M., Buhren, V., Strowitzki, M., Vastmans, J., and Maier, D (2016). Early decompression $(<8 \mathrm{~h})$ after traumatic cervical spinal cord injury improves functional outcome as assessed by spinal cord independence measure after one year. J. Neurotrauma 33, 1658-1666.

59. Mattiassich, G., Gollwitzer, M., Gaderer, F., Blocher, M., Osti, M., Lill, M., Ortmaier, R., Haider, T., Hitzl, W., Resch, H., and AschauerWallner, S. (2017). Functional outcomes in individuals undergoing very early $(<5 \mathrm{~h})$ and early $(5-24 \mathrm{~h})$ surgical decompression in traumatic cervical spinal cord injury: analysis of neurological improvement from the Austrian Spinal Cord Injury Study. J. Neurotrauma 34 3362-3371.

60. Aarabi, B., Alexander, M., Mirvis, S.E., Shanmuganathan, K., Chesler, D., Maulucci, C., Iguchi, M., Aresco, C., and Blacklock, T. (2011). Predictors of outcome in acute traumatic central cord syndrome due to spinal stenosis. J. Neurosurg. Spine 14, 122-130.

61. Boldin, C., Raith, J., Fankhauser, F., Haunschmid, C., Schwantzer, G., and Schweighofer, F. (2006). Predicting neurologic recovery in cervical spinal cord injury with postoperative MR imaging. Spine 31, 554-559.

62. Farhadi, H.F., Kukreja, S., Minnema, A., Vatti, L., Gopinath, M., Prevedello, L., Chen, C., Xiang, H., and Schwab, J.M. (2018). Impact of admission imaging findings on neurological outcomes in acute cervical traumatic spinal cord injury. J. Neurotrauma

63. Furlan, J.C., Noonan, V., Cadotte, D.W., and Fehlings, M.G. (2011). Timing of decompressive surgery of spinal cord after traumatic spinal cord injury: an evidence-based examination of pre-clinical and clinical studies. J. Neurotrauma 28, 1371-1399.

64. Batchelor, P.E., Wills, T.E., Skeers, P., Battistuzzo, C.R., Macleod, M.R., Howells, D.W., and Sena, E.S. (2013). Meta-analysis of preclinical studies of early decompression in acute spinal cord injury: a battle of time and pressure. PloS one 8, e72659.

65. Batchelor, P.E., Kerr, N.F., Gatt, A.M., Cox, S.F., Ghasem-Zadeh, A., Wills, T.E., Sidon, T.K., and Howells, D.W. (2011). Intracanal pressure in compressive spinal cord injury: reduction with hypothermia. J. Neurotrauma 28, 809-820.

66. Sewell, M.D., Vachhani, K., Alrawi, A. and Williams, R. (2018) Results of early and late surgical decompression and stabilization for acute traumatic cervical spinal cord injury in patients with concomitant chest injuries. World Neurosurg. 118, e161-e165.

67. Sapkas, G.S., and Papadakis, S.A. (2007). Neurological outcome following early versus delayed lower cervical spine surgery. J. Orthop. Surg. (Hong Kong) 15, 183-186.

68. Dvorak, M.F., Noonan, V.K., Fallah, N., Fisher, C.G., Finkelstein, J., Kwon, B.K., Rivers, C.S., Ahn, H., Paquet, J., Tsai, E.C., Townson, A., Attabib, N., Bailey, C.S., Christie, S.D., Drew, B., Fourney, D.R., Fox, R., Hurlbert, R.J., Johnson, M.G., Linassi, A.G., Parent, S., and Fehlings, M.G. (2015). The influence of time from injury to surgery on motor recovery and length of hospital stay in acute traumatic spinal cord injury: an observational Canadian cohort study. J. Neurotrauma 32, 645-654.

69. Bourassa-Moreau, E., Mac-Thiong, J.M., Li, A., Ehrmann Feldman, D., Gagnon, D.H., Thompson, C., and Parent, S. (2016). Do patients with complete spinal cord injury benefit from early surgical decompression? Analysis of neurological improvement in a prospective cohort study. J. Neurotrauma 33, 301-306.

70. Guest, J., Eleraky, M.A., Apostolides, P.J., Dickman, C.A., and Sonntag, V.K. (2002). Traumatic central cord syndrome: results of surgical management. J. Neurosurg. 97, 25-32.

71. Lenehan, B., Fisher, C.G., Vaccaro, A., Fehlings, M., Aarabi, B., and Dvorak, M.F. (2010). The urgency of surgical decompression in acute central cord injuries with spondylosis and without instability. Spine 35, Suppl. 21, S180-S186.

72. Wilson, J.R., Singh, A., Craven, C., Verrier, M.C., Drew, B., Ahn, H., Ford, M., and Fehlings, M.G. (2012). Early versus late surgery for traumatic spinal cord injury: the results of a prospective Canadian cohort study. Spinal Cord 50, 840-843.

73. Kim, M., Hong, S.K., Jeon, S.R., Roh, S.W., and Lee, S. (2018). Early $(</=48$ hours) versus late ( $>48$ hours) surgery in spinal cord injury: treatment outcomes and risk factors for spinal cord injury. World Neurosurg. 118, e513-e525.

74. Schaefer, D.M., Flanders, A.E., Osterholm, J., and Northrup, B.E. (1992). Prognostic significance of magnetic resonance imaging in the acute phase of cervical spine injury. J. Neurosurg. 76, 218-223.

75. Flanders, A.E., Schaefer, D.M., Doan, H.T., Mishkin, M.M., Gonzalez, C.F., and Northrup, B.E. (1990). Acute cervical spine trauma: correlation of MR imaging findings with degree of neurologic deficit. Radiology 177, 25-33.

76. Flanders, A.E., Spettell, C.M., Friedman, D.P., Marino, R.J., and Herbison, G.J. (1999). The relationship between the functional abilities of patients with cervical spinal cord injury and the severity of damage revealed by MR imaging. AJNR. Am. J. Neuroradiol. 20, 926-934.

77. Talbott, J.F., Whetstone, W.D., Readdy, W.J., Ferguson, A.R., Bresnahan, J.C., Saigal, R., Hawryluk, G.W., Beattie, M.S., Mabray, M.C., Pan, J.Z., Manley, G.T., and Dhall, S.S. (2015). The Brain and Spinal Injury Center score: a novel, simple, and reproducible method for assessing the severity of acute cervical spinal cord injury with axial T2-weighted MRI findings. J. Neurosurg. Spine, 1-10.

78. Farhadi, H.F., Minnema, A.J., Talbott, J.F., and Aarabi, B. (2018). Letter to the Editor: What has been learned from magnetic resonance imaging examination of the injured human spinal cord: a Canadian perspective. J. Neurotrauma

79. Phang, I., Mada, M., Kolias, A.G., Newcombe, V.F., Trivedi, R.A., Carpenter, A., Hawkes, R.C., and Papadopoulos, M.C. (2016). Magnetic resonance imaging of the codman microsensor transducer used for intraspinal pressure monitoring: findings from the Injured Spinal Cord Pressure Evaluation Study. Spine 41, E605-610. 
80. Saadoun, S., Bell, B.A., Verkman, A.S., and Papadopoulos, M.C. (2008). Greatly improved neurological outcome after spinal cord compression injury in AQP4-deficient mice. Brain 131, 1087-1098.

81. Saadoun, S., Werndle, M.C., Lopez de Heredia, L., and Papadopoulos, M.C. (2016). The dura causes spinal cord compression after spinal cord injury. Br. J. Neurosurg. 30, 582-584.

82. Freund, P., Friston, K., Thompson, A.J., Stephan, K.E., Ashburner, J., Bach, D.R., Nagy, Z., Helms, G., Draganski, B., Mohammadi, S., Schwab, M.E., Curt, A., and Weiskopf, N. (2016). Embodied neurology: an integrative framework for neurological disorders. Brain 139, 1855-1861.

83. Freund, P., Weiskopf, N., Ashburner, J., Wolf, K., Sutter, R., Altmann, D.R., Friston, K., Thompson, A., and Curt, A. (2013). MRI investigation of the sensorimotor cortex and the corticospinal tract after acute spinal cord injury: a prospective longitudinal study. Lancet Neurol. 12, 873-881.

84. Mohammadi, S., Freund, P., Feiweier, T., Curt, A., and Weiskopf, N. (2013). The impact of post-processing on spinal cord diffusion tensor imaging. Neuroimage 70, 377-385.

85. Seif, M., Ziegler, G. and Freund, P. (2018). Progressive ventricles enlargement and cerebrospinal fluid volume increases as a marker of neurodegeneration in patients with spinal cord injury: a longitudinal magnetic resonance imaging study. J. Neurotrauma

86. Shanmuganathan, K., Gullapalli, R.P., Zhuo, J., and Mirvis, S.E. (2008). Diffusion tensor MR imaging in cervical spine trauma. AJNR Am. J. Neuroradiol. 29, 655-659.

87. Shanmuganathan, K., Zhuo, J., Chen, H.H., Aarabi, B., Adams, J., Miller, C., Menakar, J., Gullapalli, R.P., and Mirvis, S.E. (2017). Diffusion tensor imaging parameter obtained during acute blunt cer- vical spinal cord injury in predicting long-term outcome. J. Neurotrauma 34, 2964-2971.

88. Nout, Y.S., Mihai, G., Tovar, C.A., Schmalbrock, P., Bresnahan, J.C., and Beattie, M.S. (2009). Hypertonic saline attenuates cord swelling and edema in experimental spinal cord injury: a study utilizing magnetic resonance imaging. Crit. Care Med. 37, 2160-2166.

89. Salegio, E.A., Bresnahan, J.C., Sparrey, C.J., Camisa, W., Fischer, J., Leasure, J., Buckley, J., Nout-Lomas, Y.S., Rosenzweig, E.S., Moseanko, R., Strand, S., Hawbecker, S., Lemoy, M.J., Haefeli, J., Ma, X., Nielson, J.L., Edgerton, V.R., Ferguson, A.R., Tuszynski, M.H., and Beattie, M.S. (2016). A unilateral cervical spinal cord contusion injury model in non-human primates (Macaca mulatta). J. Neurotrauma 33, 439-459.

90. Chou, P.C., Shunmugavel, A., El Sayed, H., Desouki, M.M., Nguyen, S.A., Khan, M., Singh, I., and Bilgen, M. (2011). Preclinical use of longitudinal MRI for screening the efficacy of S-nitrosoglutathione in treating spinal cord injury. J. Magn. Reson. imaging 33, 1301-1311.

Address correspondence to:

Bizhan Aarabi, MD, FRCSC, FACS

R. Adams Cowley Shock Trauma Center

Department of Neurosurgery

University of Maryland School of Medicine

22 South Greene Street, Suite S-12-D

Baltimore, MD 21201

E-mail: baarabi@som.umaryland.edu 